\title{
Configurações
}

Revista de sociologia

14 | 2014

Para além da Governação. Políticas, práticas e discursos de inclusão e promoção da diversidade cultural

\section{No tendrás dioses ajenos delante de mí: notas sobre la diferenciación y la intolerancia religiosas en México}

Não terás outros deuses diante de mim: notas sobre a diferenciação e a intolerância religiosa

You shall have no other gods before me: notes on differentiation and religious intolerance in Mexico

\section{Francesco Gervasi}

\section{(2) OpenEdition}

Edición electrónica

URL: http://journals.openedition.org/configuracoes/2341

DOI: 10.4000/configuracoes.2341

ISSN: $2182-7419$

Editor

Centro de Investigação em Ciências Sociais

\section{Edición impresa}

Paginación: 177-198

ISBN: 1646-5075

ISSN: 1646-5075

\section{Referencia electrónica}

Francesco Gervasi, « No tendrás dioses ajenos delante de mí: notas sobre la diferenciación y la intolerancia religiosas en México », Configurações [En línea], 14 | 2014, Puesto en línea el 30 marzo 2015, consultado el 20 abril 2019. URL : http://journals.openedition.org/configuracoes/2341 ; DOI 10.4000/configuracoes.2341

Este documento fue generado automáticamente el 20 abril 2019. 


\section{No tendrás dioses ajenos delante de mí: notas sobre la diferenciación y la intolerancia religiosas en México}

Não terás outros deuses diante de mim: notas sobre a diferenciação e a intolerância religiosa

You shall have no other gods before me: notes on differentiation and religious intolerance in Mexico

Francesco Gervasi

\section{Introducción}

1 Este artículo se basa en una investigación descriptiva (Hernández Sampieri, Collado, Baptista, 2010: 80-81; Mertens, 2010: 115; Orozco y González, 2011: 37) y exploratoria (Hernández Sampieri, Collado, Baptista, 2010: 79-80; Orozco y González, 2011: 37), cuyos objetivos $^{1}$ específicos o propósitos son:

2 1. Reconstruir los procesos de diferenciación del campo religioso mexicano, desde las primeras manifestaciones de religiones no católicas hasta el 2010;

3 2. Describir las principales prácticas de intolerancia hacia las minorías religiosas, presentes en México;

4 3. Determinar en cuáles tipologías del racismo pueden ubicarse estas prácticas.

5 Para ello utilizaremos las estadísticas oficiales (los datos del INEGI y los datos proporcionados por la Dirección General de Asuntos Religiosos) y no oficiales (la encuesta sobre discriminación de la CONAPRED) ya existentes (Corbetta, 2007: 252). Hemos seleccionado estas fuentes porque, entre las pocas disponibles, son las más recientes. La aspiración final del trabajo es ofrecer un marco de referencia actualizado sobre estas dos temáticas ${ }^{2}$ que, aun sin pretender ser exhaustivo, pueda representar un punto de partida para una mejor comprensión de las complejas dinámicas religiosas presentes en este país 
$\mathrm{y}$, consecuentemente, para el desarrollo de futuras investigaciones empíricas sobre este tema en México y, en una perspectiva comparativa, en otros contextos socio-religiosos. Nos parece importante abordar estas temáticas porque, como lo ha destacado Nesti (1993), también en las sociedades contemporáneas, el factor religioso representa un elemento fundamental "que puede permitir explorar los subterráneos de la sociedad y comprender el sutil dinamismo humano frente y dentro la vida del mundo" (p. 7).

En cuanto a la estructura del trabajo, en el primer apartado, presentaremos algunas reflexiones sobre el concepto de "pluralismo religioso" que, en sociología, viene generalmente utilizado para describir la tendencia hacia la diversificación del sistema religioso contemporáneo. El segundo será dedicado a la diferenciación del campo religioso mexicano, sus premisas y su desarrollo actual. En el tercero, se presentarán algunas reflexiones teóricas en torno al concepto de "racismo" y sus formas de expresión. En el cuarto, enfocaremos la atención en las prácticas de intolerancia hacia los grupos religiosos minoritarios y determinaremos en cuáles tipologías del racismo pueden ubicarse dichas prácticas.

7 Finalmente, en las conclusiones, se sintetizarán los puntos más importantes abordados en el artículo.

\section{Características del factor religioso en la modernidad: el imperativo herético, el convertido y el pluralismo religioso}

Como lo ha hecho notar Davie (2011),

Tanto en el discurso popular como en el sociológico, el pluralismo religioso (...) se refiere a la creciente fragmentación de los sistemas de creencia, circunstancia que, según ya hemos mencionado, constituye una de las posibles manifestaciones de la religión en la tardomodernidad. (p. 206)

9 En otras palabras, el pluralismo religioso representa una de las consecuencias de la afirmación de la conciencia moderna que, según Peter Berger (1987), "Implica un movimiento desde el destino hacia la elección" (p.49), y es por ello que, según este autor, la afirmación de la modernidad ha implicado el triunfo del imperativo herético, palabra que, recuperando del griego su etimología, haireisthai, signifi ca precisamente "hacer la propia elección". Berger (1987) sostiene que si

Para el hombre premoderno la herejía era una posibilidad generalmente bastante remota; para el hombre moderno la herejía se convierte específi camente en una necesidad. Aún más, la modernidad crea una nueva situación en la cual elegir se convierte en un imperativo. (p. 61)

10 Para el hombre moderno, entonces, elegir se convierte casi en un deber. La ampliación de la posibilidad de elegir se da en un contexto en el cual se multiplican las opciones de elección. Eso porque, según Berger (1987), "La modernidad pluraliza, tanto las instituciones como las estructuras de plausibilidad” (p. 54). El pluralismo en general, según Berger y Luckmann (1997), consiste en "la coexistencia de distintos sistemas de valores, y fragmentos de dichos sistemas, en una misma sociedad, y ( ) la existencia simultánea de comunidades de sentido completamente diferentes" (p. 54). Cuando el pluralismo "se transforma en un valor supraordinal para una sociedad, podemos hablar de pluralismo moderno" (Berger y Luckmann, 1997: 57). La modernidad pluraliza en todos las esferas sociales: la económica, la política, la cultural, y también la religiosa. En esta 
última, el "triunfo" del imperativo herético se traduce en la tendencia por parte de los creyentes a elegir, en lugar de aceptar o heredar pasivamente, su propia religión. En otros términos, tiende a afirmarse un contexto religioso en el cual

La petición de una "religión elegida", que pone en evidencia la experiencia personal y la autenticidad de un trayecto de búsqueda en lugar que la preocupación de la conformidad a las verdades religiosas garantizadas por una institución, es coherente con la llegada de una modernidad psicológica que implica para el hombre un cierto modo de pensarse como individualidad y de operar para conquistar una identidad personal, más allá de cada identidad heredada o prescrita. (HervieuLéger, 2003: 52)

11 La fi gura ejemplar de creyente que, según Hervieu Léger, se impone con fuerza en la situación existencial moderna es, entonces, la del convertido, definido justamente como aquel tipo de creyente que elige su propia identidad religiosa en lugar de aceptarla como una herencia pasiva. Como consecuencia de la situación arriba descrita, el campo religioso tiende a funcionar como un mercado económico en el cual la religión, inevitablemente, se transforma en un bien de consumo (Filoramo, 2005: 15) y las varias confesiones religiosas se convierten en empresas que buscan conquistar, por medio de la diferenciación de sus propuestas (la oferta), el número más amplio de seguidores (la demanda) disponibles en el mercado. Berger y Luckmann (1997) sintetizan lo anterior con las siguientes palabras:

El pluralismo moderno ha socavado el monopolio del que disfrutaban las instituciones religiosas. Ya sea que les guste o no, ellas son proveedoras en un mercado de opciones religiosas. (...) Si desean sobrevivir, las Iglesias necesitan tener en cuenta cada vez más los anhelos de sus miembros. Las iglesias deben probarse a sí mismas en el mercado libre. La gente que "compra" una determinada fe constituye un grupo de consumidores. (pp. 89-90)

\section{La diferenciación del panorama religioso mexicano}

A partir de la primera década del 1990, varios autores han empezado a destacar la tendencia hacia la pluralización del campo religioso latinoamericano (Adogame, 2010; Aubrée, 2013; Bastian, 2011a; Bastian, 2011b; Chesnut, 2003; Freston, 2007; Gill, 1998; Martin, 1990; Martin, 2002; Stoll, 1990) y, más específicamente, mexicano (De la Torre y Zúniga, 2007; Fortuny, 1993; Garma Navarro, 1987; Garma Navarro, 2004; Garma Navarro y Leatham, 2004; Scott, 1997), enfocándose sobre todo en el fenómeno de las iglesias y movimientos de tipo protestante.

13 Esta tendencia hacia la fragmentación del contexto religioso latinoamericano empieza, según Bastian (2011a: 82), a partir de la década de 1950, principalmente como consecuencia de la "globalización y la internacionalización de las comunicaciones y por la revolución tecnológica, que permite enviar personas, mensajes y programas al mundo entero" (Bastian, 2011a: 83). El resultado de este proceso es "una verdadera transnacionalización de lo religioso con influencias recíprocas a escala mundial" (Bastian, 2011a: 83), en la cual América Latina no es sólo receptora de nuevos movimientos religiosos foráneos, sino que es también creadora de estas nuevas realidades que se difunden en todo el planeta. Según Bastian (2011a: 85-97), existen también motivos endógenos que explican el proceso de pluralización del mercado religioso latinoamericano. En el ámbito económico, cada vez más caracterizado por nuevas y más feroces desigualdades producto de la modernización, son sobre todo los marginados y los 
excluidos quienes buscan en los nuevos bienes simbólicos de tipo religioso, la posibilidad de reconstruir la propia identidad y el propio proyecto de vida. En cambio, en sistemas políticos dominados por el predominio de relaciones neopatrimoniales y una escasa movilización social,

Lo religioso puede servir a la vez a la construcción de un espacio de organización en medio de la anomia general que prevalece entre estos sectores empobrecidos y a la ampliación del espacio de impugnación, como la sociología de la religión lo ha señalado en el caso de los movimientos mesiánicos y milenaristas. Por lo menos puede propiciar la estructuración de nuevos recursos organizativos de negociación con el poder político en turno (Bastian, 2001a: 93).

En el campo religioso, en fi n, la proliferación de nuevas opciones refleja el desencanto de las masas con una Iglesia católica radical y conciliadora con el poder político.

Todos estos factores, exógenos y endógenos, han impulsado el surgimiento de nuevas opciones religiosas que, como hemos mencionado arriba, han empezado a pluralizar el contexto latinoamericano a partir de los años '50 del 1900. México no representa una excepción. A continuación, se presenta una tabla que sintetiza el crecimiento de la población con religión diferente a la católica en México, desde el 1950 hasta el 2010:

Tabla 1.

Crecimiento de la población con religión diferente de la católica 1950-2010*

\begin{tabular}{|c|c|c|c|}
\hline & $\begin{array}{c}\text { \% } \\
\text { Cańlicos }\end{array}$ & $\begin{array}{c}\text { \% } \\
\text { Religiones diferentes } \\
\text { a la católica }\end{array}$ & $\begin{array}{c}\text { \% } \\
\text { Sin religión }\end{array}$ \\
\hline 1950 & 98,22 & 1,78 & ND \\
\hline 1960 & 96,51 & 2,32 & 0,55 \\
\hline 1970 & 96,23 & 2,22 & 1,59 \\
\hline 1980 & 92,60 & 4,24 & 3,12 \\
\hline 1990 & 89,73 & 6,42 & 3,23 \\
\hline 2000 & 88,22 & 7,71 & 3,49 \\
\hline 2010 & 82,70 & 9,86 & 4,68 \\
\hline
\end{tabular}

Fuente: Elaboración realizada a partir de INEGI (2010).

* Se omitió la categoría "no especificado".

Como se puede notar, el crecimiento de la población con religión diferente a la católica, a partir de los años '50, ha sido constante (desde el 1,78\% del 1950 hasta el 9,86 del 2010), mientras que, por lo menos en una perspectiva de largo plazo, aparece también evidente el lento declive del catolicismo (desde el 98,22\% del 1950 hasta el 82,70 del 2010). Es también interesante destacar el incremento del porcentaje de los "sin religión", quienes, como lo ha hecho notar Dobbelaere (2004: 195), en las modernas sociedades secularizadas, podrían reflejar la postura de aquellas personas que, en un mercado de los bienes simbólicos cada vez más abierto, heterogéneo y plural (Luckmann, 1969), producto de la afirmación del "politeísmo de los valores" (Weber, 2009), para dar sentido a sus vidas, eligen visiones del mundo laicas. Volviendo a la diferenciación del panorama religioso, en 
la siguiente tabla aparecen las confesiones más importantes que, como parte de la tabla anterior, conforman la categoría "religiones diferentes a la católica":

Tabla 2.

Porcentajes de población con religión diferente a la católica (1950-2010) desglosado por protestantes y otras religiones*

\begin{tabular}{|c|c|c|c|c|}
\hline \multirow{2}{*}{ Año } & $\begin{array}{c}\text { \% } \\
\text { Católicos }\end{array}$ & $\begin{array}{c}\% \\
\text { Protestante/ } \\
\text { Evangélica }\end{array}$ & $\begin{array}{c}\% \\
\text { Otras }\end{array}$ & $\begin{array}{c}\% \\
\text { Sin religión }\end{array}$ \\
\hline 1950 & 98,22 & 1,28 & 0,50 & ND \\
\hline 1960 & 96,51 & 1,65 & 0,67 & 0,55 \\
\hline 1970 & 96,23 & 1,81 & 0,41 & 1,59 \\
\hline 1980 & 92,60 & 3,29 & 0,95 & 3,12 \\
\hline 1990 & 89,73 & 4,89 & 1,53 & 3,23 \\
\hline 2000 & 88,22 & 5,21 & 2,50 & 3,49 \\
\hline 2010 & 82,70 & 7,46 & 2,40 & 4,68 \\
\hline
\end{tabular}

Fuente: Elaboración realizada a partir de INEGI (2010).

* Se omitió la categoría "no especificado".

Con base en los datos del INEGI, el grupo que ha impulsado mayormente la pluralización del sistema religioso mexicano, por lo menos en los últimos 30 años, es el que incluye protestantes y evangélicos (desde el 1,28\% del 1950 al 7,46\% del 2010).

En México, la aparición de los primeros movimientos y asociaciones de tipo protestante se remonta a los años sesenta del siglo XIX, inicialmente en zonas esencialmente rurales, caracterizadas por una tradición política liberal radical (Bastian, 2011b: 115). Como lo ha hecho notar Bastian (2011b), estos primeros protestantes mexicanos formaban parte de "sectores sociales en transición, cuyos intereses religiosos disidentes coincidían con las reivindicaciones de autonomía regional y de una cultura política liberal, característica de los medios rurales en vías de modernización y de los nuevos sectores urbanos" (p. 117). Era un protestantismo que, por lo tanto, "amenazaba el poder y los derechos tradicionales" en ámbito rural, y que se relacionaba "con la formación de una clase obrera en busca de una cultura religiosa moderna y de nexos de solidaridad asociativa, capaz de ofrecer servicios escolares y religiosos a poblaciones que emigraban constantemente de centro en centro de trabajo" (Bastian, 2011b: 117-118) en ámbito urbano. El desarrollo de estos grupos fue impulsado, sobre todo, durante la presidencia de Benito Juárez (1858-1872), quien autorizó la difusión legal del protestantismo en el país para debilitar a una Iglesia Católica que se oponía a los programas liberales (Garma Navarro, 2004: 50). Sin embargo, es sólo a partir de la mitad del 1900 que los protestantes lograron establecerse firmemente (Garma Navarro, 2004: 48) en territorio mexicano. Desde entonces y hasta la fecha, su presencia en México ha crecido de manera significativa, y el dato más interesante que vale la pena destacar al respecto, según Roberto Blancarte (2010), es que desde el 1950 hasta el 2010:

La tasa de crecimiento de los católicos fue menor a la tasa de crecimiento de la población, mientras que la tasa de crecimiento de protestantes y evangélicos y de otras religiones fue mayor. En otras palabras, de continuar dicha tendencia durante 
las siguientes décadas, como ya sucede en otros países latinoamericanos, México podría llegar a ser un país más cristiano que católico, con profundas consecuencias sociales, políticas e identitarias". (p. 92)

Para concluir esta parte dedicada a la reconstrucción de los procesos de diferenciación del campo religioso mexicano, vale la pena proveer un cuadro de la distribución territorial actual de la diversidad religiosa en el país. En la siguiente tabla, se destacan las principales identidades religiosas presentes en los 32 Estados mexicanos, en el 2010.

Tabla 3

Panorama de la diversidad religiosa

presente en los 32 estados de la república mexicana en el 2010*’

\begin{tabular}{|l|c|c|c|c|}
\hline Entidad & $\begin{array}{c}\% \\
\text { Católicos }\end{array}$ & $\begin{array}{c}\% \\
\text { Protestantes } \\
\text { y evangélicos }\end{array}$ & $\begin{array}{c}\% \\
\text { Otras }\end{array}$ & $\begin{array}{c}\% \\
\text { rin }\end{array}$ \\
\hline religión
\end{tabular}




\begin{tabular}{|c|c|c|c|c|}
\hline Entidad & $\begin{array}{c}\% \\
\text { Católicos }\end{array}$ & $\begin{array}{c}\% \\
\text { Protestantes } \\
\text { y evangélicos }\end{array}$ & $\begin{array}{c}\% \\
\text { Otras }\end{array}$ & $\begin{array}{c}\% \\
\text { Sin } \\
\text { religión }\end{array}$ \\
\hline Hidalgo & 86,89 & 6,74 & 1,69 & 2,36 \\
\hline Jalisco & 91,99 & 3,18 & 1,25 & 1,69 \\
\hline México & 85,39 & 5,61 & 1,89 & 3,20 \\
\hline Michoacán de Ocampo & 91,55 & 3,11 & 1,33 & 1,91 \\
\hline Morelos & 77,99 & 9,51 & 3,47 & 6,10 \\
\hline Nayarit & 88,25 & 4,92 & 2,12 & 3,41 \\
\hline Nuevo León & 82,39 & 8,22 & 2,08 & 4,13 \\
\hline Oaxaca & 80,61 & 10,50 & 2,81 & 4,45 \\
\hline Puebla & 88,32 & 5,82 & 1,78 & 1,80 \\
\hline Querétaro & 91,94 & 3,22 & 1,14 & 2,08 \\
\hline Quintana Roo & 63,30 & 14,45 & 4,79 & 13,37 \\
\hline San Luis Potosí & 88,93 & 5,73 & 1,14 & 2,26 \\
\hline Sinaloa & 83,82 & 5,08 & 2,33 & 7,31 \\
\hline Sonora & 82,28 & 7,65 & 2,05 & 6,54 \\
\hline Tabasco & 64,53 & 18,37 & 5,64 & 9,48 \\
\hline Tamaulipas & 72,93 & 12,16 & 2,53 & 6,72 \\
\hline Tlaxcala & 90,81 & 4,11 & 1,76 & 1,27 \\
\hline Veracruz de Ignacio de la Llave & 78,69 & 9,19 & 3,43 & 6,48 \\
\hline Yucatán & 79,50 & 10,79 & 3,29 & 4,77 \\
\hline Zacatecas & 93,53 & 2,80 & 1,07 & 1,21 \\
\hline
\end{tabular}

Fuente: Elaboración realizada a partir de INEGI (2010).

* Se omitió la categoría "no especificado".

Como se puede notar, el panorama religioso mexicano actual es muy heterogéneo. Hay estados como Campeche, Chiapas, Quintana Roo y Tabasco, en los cuales el porcentaje de católicos queda por debajo del $65 \%$ (es decir, casi $18 \%$ menos del promedio nacional) y, sobre todo, las religiones no católicas representan una quinta parte de la población total. Además, en estos 4 estados, se registran los porcentajes más altos de "protestantes y evangélicos" (arriba del 14\%). En cambio, hay otros (Aguascalientes, Guanajuato, Jalisco, Michoacán, Querétaro, Tlaxcala, Zacatecas) en los cuales el porcentaje de católicos está por arriba del $90 \%$ y el de las religiones no católicas por debajo del 5\%, reflejando, por lo tanto, una menor tendencia hacia la diversificación religiosa con respecto al promedio nacional. Es también interesante destacar la presencia muy significativa de "los sin religión", que en Chiapas, Campeche y Quintana Roo alcanzan porcentajes arriba del $10 \%$.

21 En general, emerge un cuadro bastante complejo, caracterizado por la presencia de diferentes opciones, que confirman, en el nivel estatal, la tendencia hacia la diversificación del campo religioso mexicano.

\section{De la intolerancia al racismo: algunas reflexiones teóricas}

En este apartado, definiremos algunos conceptos clave para poder interpretar los datos relativos a la intolerancia religiosa presente en el país. Si definimos la tolerancia como: "la elección deliberada de no interferir en conductas y creencias, estilos de vida y comportamientos, que uno desaprueba" (Karstedt, 2009: 5020), entonces, la intolerancia, en cuanto versión negativa de la tolerancia, puede ser definida simplemente como: "la elección deliberada de interferir en conductas y creencias, estilos de vida y 
comportamientos, que uno desaprueba". Una de las formas mediante las cuales, históricamente, se ha manifestado la intolerancia, es el racismo que, según Wieviorka (2009: 13), "consiste en caracterizar un conjunto humano mediante atributos naturales, asociados a su vez a características intelectuales y morales aplicables a cada individuo relacionado con este conjunto $\mathrm{y}$, a partir de ahí, adoptar algunas prácticas de inferiorización y exclusión".

Complementaremos la definición de Wieviorka con el concepto, más pertinente con los objetivos de nuestro estudio, de "racismo cultural" de Barker (1981), es ecir aquel tipo de racismo que, para justificar los prejuicios, la discriminación y los actos de violencia, utiliza no sólo las diferencias físicas sino principalmente las culturales (religión, tradiciones, costumbres, creencias, etc.). Siempre según Wieviorka (2009: 69-85), el racismo tiende a expresarse, principalmente, a través de tres formas: la segregación, la discriminación y el prejuicio. La primera práctica, designa "a la vez un proceso y su resultado, que sufre un grupo mantenido a distancia, localizado en espacios propios que le son reservados, enclaves, guetos, territorios de uno u otro tipo" (Wieviorka, 2009: 79). La segunda (la discriminación), consiste "en poner de relieve la raza para otorgarle un tratamiento diferenciado" (Wieviorka, 2009: 83). El prejuicio, finalmente, remite a "representaciones del Otro que valorizan el ingroup (grupo de pertenencia, también llamado endogrupo) en vez del outgroup (grupo distinto, también llamado exogrupo), que amplían las diferencias y desembocan en estereotipos susceptibles de alimentar o justificar actitudes discriminatorias" (Wieviorka, 2009: 72).

Entre finales de los años setenta e inicios de los ochenta del siglo XX, algunos autores (Kinder y Sears, 1981; Pettigrew, 1989) señalaron que el racismo se estaba volviendo cada vez más sutil, indirecto y latente. Kinder y Sears (1981: 416) han definido esta nueva forma de racismo, llamada racismo simbólico, como

una mezcla de afecto antinegro y de defensa de los valores morales tradicionales americanos que están personificados en la ética protestante ( ) una forma de resistencia al cambio en el status quo racial basada en sentimientos morales de que los negros violan algunos valores tradicionales americanos tales como el individualismo, la confianza en sí mismo, la ética del trabajo, la obediencia y la disciplina.

Es un racismo que, basándose en la idea de que el grupo subordinado está amenazando los valores fundamentales de toda una sociedad, es más latente y, a la vez, puede resultar más eficaz y poderoso.

Muy a menudo, el racismo tiende a manifestarse mediante formas, más o menos explícitas, de violencia. Una útil clasificación de los varios tipos de racismo, basada en los diferentes niveles de violencia y de penetración en la sociedad y en las instituciones, es la siguiente (Wieviorka, 2009: 105-107): 1) el infrarracismo, que se caracteriza por formas de racismo débil, la violencia es muy localizada, los prejuicios y los rumores no tienen alcance práctico, la discriminación y la segregación están limitadas. 2) El racismo disperso, que se basa en formas de racismo más tangible, afirmado y organizado. Las ideologías y doctrinas racistas se difunden más allá de los círculos de iniciados, la segregación y la discriminación son explícitas y evidentes, la violencia es más frecuente y sangrienta.

3) El racismo institucionalizado y/o político, cuando el racismo penetra en las instituciones, las cuales contribuyen, de manera más o menos activa, a la discriminación y a la segregación ${ }^{3}$. Las ideas racistas pueden llegar a invadir también la vida política, 
jugando un papel fundamental en los debates que la animan. 4) El racismo total, cuando el fenómeno penetra en toda la sociedad hasta la cima del Estado, el cual se organiza en función de una ideología racista.

Igualmente interesante es la distinción que Wieviorka (2009: 94-104) propone entre orígenes sociales y orígenes identitarios de la violencia racista. El primer tipo de violencia se relaciona "siempre con el esfuerzo de algunos grupos, bien para mantener o asentar una posición dominante o bien para evitar o frenar la caída, la pauperización o la exclusión social" (Wieviorka, 2009: 94). El segundo, en cambio, es un tipo de violencia que se construye, de una manera defensiva u ofensiva, a partir de una dimensión principalmente cultural. Como destacado por Wieviorka (2009):

Cuando es defensiva, expresa la reacción ante un sentimiento de amenaza que pesa sobre la identidad colectiva, sea ésta definida en términos de nación, de religión o de comunidad. Cuando es ofensiva o contraofensiva, se afirma reduciéndola a la idea de una naturaleza, una conciencia identitaria que acompaña o sostiene un proceso de expansión, como así sucedió con diversas expresiones del racismo colonial. (pp. 99-100)

La violencia racista, a veces, puede desembocar en la eliminación sistemática de las minorías. Eso puede pasar cuando estamos en presencia de las que Appadurai (2007: 69) defi ne como "identidades predatorias". Estas últimas son identidades mayoritarias que surgen cuando, en una sociedad, se afirma la idea según la cual la

singularidad del pueblo nacional se reduce con éxito al principio de singularidad étnica, de modo que incluso la existencia de la minoría más pequeña dentro de los límites de la nación es considerado como un déficit de pureza en el todo nacional. (Appadurai, 2007: 71-72)

Las posibles consecuencias de esta idea se pueden fácilmente prever: violencia, conflictos, limpiezas étnicas, genocidio.

Antes de terminar esta parte, vale la pena destacar que utilizaremos un enfoque según el cual, como planteado por Blumer (1958: 3), los prejuicios raciales nunca proceden del interés personal, sino del sentimiento colectivo de que el propio grupo está siendo amenazado por parte del grupo subordinado y que hay que reaccionar para defenderlo, para defender los privilegios, la pureza y la posición del grupo dominante (Blumer, 1958: 5).

\section{5. “¿Prostituta? ¡Ah, bueno! Yo creía que habías dicho protestante": la intolerancia hacia las minorías religiosas en México}

32 A pesar de los datos hasta ahora proporcionados, en México, la mayoría de la población sigue siendo católica $(82,70 \%)$. En este contexto, entonces, las religiones no-católicas siguen representando un grupo minoritario, desde el punto de vista numérico y, lo que es más importante, en cuanto a los escasos recursos de los que disponen dentro la sociedad (Giddens, 2007: 471). Históricamente, las minorías de cualquier tipo, como destacado por Appadurai (2007), han tenido que enfrentarse a lo que el sociólogo hindú llama "angustia de lo incompleto", la cual implica que:

Las mayorías numéricas pueden convertirse en predatorias y etnocidas de los números pequeños precisamente cuando algunas minorías (y sus números pequeños) recuerdan a las mayorías la pequeña brecha que media entre su 
condición de mayorías y el horizonte de un todo nacional impoluto, de una etnia nacional y sin tacha. (p. 22)

Prejuicios, discriminación y racismo, representan los medios principales que las mayorías han utilizado, y siguen utilizando, para lograr este objetivo de "un todo nacional impoluto, de una etnia nacional y sin tacha". El discurso de Appadurai, claramente, se puede aplicar también a las minorías religiosas, sobre todo en una época, como la contemporánea, caracterizada cada vez más por la difusión de "civicidios" e "ideocidios" (Appadurai, 2007). En el contexto mexicano, desde su aparición, las religiones no católicas (que, como hemos visto, son principalmente de tipo protestante) han sido víctimas de prejuicios, discriminación y hasta violencia (Blancarte, 2008; Garma Navarro, 2004; Monsiváis 2010).

Pero, antes de delinear las formas más frecuentes de intolerancia hacia las minorías religiosas presentes en el país, conviene recordar, brevemente, el marco legal encargado de tutelarlas. A tal respecto, cabe destacar que la Ley de Asociaciones Religiosas y Culto Público establece, en su artículo 2, que el Estado mexicano garantiza en favor del individuo ciertos derechos en materia religiosa, entre los cuales señala los de "No ser objeto de discriminación, coacción u hostilidad por causa de sus creencias religiosas, ni ser obligado a declarar sobre las mismas" (Blancarte, 2008: 46-47). En el artículo 3, sostiene que "El Estado no podrá establecer ningún tipo de preferencia o privilegio en favor de religión alguna. Tampoco a favor o en contra de ninguna iglesia ni agrupación religiosa". La Dirección General de Asociaciones Religiosas es la institución que, en México, debe: "Atender o promover la actividad de las instancias competentes en las denuncias de intolerancia religiosa, así como llevar el control y seguimiento de las mismas" (Blancarte, 2008: 47). Sin embargo, casi siempre, interviene sólo de forma conciliatoria (privilegiando "la vía del diálogo y la conciliación entre las partes") que ha significado, en la práctica, la impunidad de la intolerancia.

Consecuentemente, muy a menudo, los afectados prefieren no denunciar los casos de discriminación, y es por eso que los datos proporcionados por la Dirección General de Asuntos Religiosos no siempre son confiables (Blancarte, 2008: 50).

Después de haber mencionado brevemente las leyes e instituciones que deben tutelar los derechos de las religiones minoritarias, vamos ahora a enfocar la atención en el tema principal de este apartado, es decir las formas de intolerancia religiosa presentes en el país, recordando algunas tendencias generales (Blancarte, 2008: 49): 1) la intolerancia de tipo religioso se da en zonas rurales y en zonas urbanas; 2) los principales sujetos activos de la intolerancia son: individuos, grupos religiosos, organizaciones laicas privadas, los medios masivos de comunicación, el aparato estatal; 3) los principales objetos pasivos, en cambio, son: las iglesias y agrupaciones religiosas minoritarias (se ejerce contra los individuos y contra los grupos o comunidades religiosas).

Pero ¿cuáles son las conductas más frecuentes en materia de intolerancia religiosa? La Dirección General de Asuntos Religiosos de la Secretaría de Gobernación señala las siguientes: el hostigamiento por profesar creencias religiosas diferentes a las del grupo mayoritario de la comunidad; la imposición de cooperaciones, trabajos y cargos para las festividades religiosas de otra iglesia distinta a la suya; la oposición a la construcción de templos de otro credo; la suspensión de servicios públicos, como agua y panteón; la retención de cheques del Programa Progresa4; la privación de derechos agrarios; la expulsión de la comunidad; la privación ilegal de la libertad; las lesiones a los miembros de otros cultos (Blancarte, 2008: 49). Son conductas que, como se puede ver, atentan a 
todas las esferas (económica, religiosa, política) de la vida privada y pública de los integrantes de las minorías religiosas, violan sus derechos civiles, políticos y sociales (suspensión de servicios públicos, privación de la libertad, expulsión de la comunidad), hasta llegar a la violencia física. El aspecto más preocupante es la gran cantidad de conductas que implican la acción, más o menos directa, de las instituciones y que, por lo tanto, se encuadran dentro del racismo institucionalizado (Wieviorka, 2009: 107): la suspensión de servicios públicos, la retención de cheques del Programa Progresa, la privación de derechos agrarios, la expulsión de la comunidad. Además, son formas de racismo que implican tanto el uso de la violencia simbólica ${ }^{5}$ que de la física (Wieviorka, 2009: 87).

Las percepciones que tienen los integrantes de las minorías religiosas acerca de los principales problemas que afectan a las personas de su religión, confirman el cuadro arriba delineado. Veamos en la siguiente tabla cuáles son:

Tabla 4.

Principales problemas para las personas que pertenecen a grupos religiosos minoritarios

\begin{tabular}{|l|l|}
\hline \multicolumn{1}{|c|}{ PROBLEMA } & $\%$ \\
\hline Rechazo, falta de aceptación, discriminación y desigualdad & 28,7 \\
\hline Burlas, críticas y falta de respeto & 28,1 \\
\hline NS/NC & 11,5 \\
\hline Otro & 10,4 \\
\hline Ninguno & 7,0 \\
\hline Incomprensión, prejuicios o ignorancia & 6,4 \\
\hline No ser católico & 3,5 \\
\hline Pocos templos & 1,6 \\
\hline Agresión, violencia & 1,1 \\
\hline Encontrar trabajo & 0,7 \\
\hline El ser minoría & 0,6 \\
\hline El Gobierno (falta de apoyo) & 0,2 \\
\hline Rechazo por no saludar la bandera & 0,1 \\
\hline
\end{tabular}

FUENTE: CONAPRED, 2010: 110.

El primer dato que vale la pena destacar es que sólo el 7\% de los entrevistados sostiene que el formar parte de un grupo religioso minoritario no le causa ningún problema. Igualmente interesante, aun no muy alto, parece el porcentaje $(3,5 \%)$ de personas que sostienen que su principal problema es no ser católico, porque esta respuesta enfatiza el papel determinante del catolicismo, claramente percibido como religión hegemónica en el país, en los actos discriminatorios perpetrados en contra de las minorías religiosas, en el país. Los dos problemas principales son el de la discriminación ("Rechazo, falta de aceptación, discriminación y desigualdad") y de la violencia simbólica (Wieviorka, 2009: 87) ("burlas críticas y falta de respeto"), que, respectivamente, obtienen el $28,7 \%$ y el $28,1 \%$ de las respuestas. Sin embargo, no hay que subestimar el problema de la violencia física que, aun con un porcentaje bajo (1,1\%), confirma el dato destacado por La Dirección 
General de Asuntos Religiosos de la Secretaría de Gobernación, según el cual la intolerancia religiosa no se limita a las puras ofensas, burlas o falta de respeto.

Otras percepciones interesantes (CONAPRED, 2010: 112), que además confirman una situación bastante problemática para las minorías religiosas en México, son las siguientes: el 43\% de los entrevistados pertenecientes a alguna minoría religiosa sostiene que, en este país, no se respetan los derechos de las minorías religiosas; el 39,5\% sostiene que la gente de su ciudad o pueblo no acepta que ellos usen vestimentas o accesorios que los distingan; uno de cada cuatro (el 25,7\%) entrevistados sostiene que la gente de su ciudad o pueblo no acepta que ellos realicen ceremonias o prácticas propias de su religión; los actores sociales que los entrevistados sostienen ser más intolerantes son: la gente de su barrio o colonia $(11,9 \%)$, los medios de comunicación $(6,5 \%)$ y la policía $(5,6 \%)$. Es muy interesante destacar como estas percepciones (de los integrantes de las minorías religiosas) no coincidan con la apertura hacia la diversidad religiosa manifestada por parte del 70,3\% de la población nacional, que considera positivo que "la sociedad esté compuesta por personas de religiones diferentes". En este caso, por lo tanto, parece emerger aquel racismo simbólico que, como planteado por Kinder y Sears (1981), tiende a manifestarse de manera más sutil y latente, pero igualmente peligrosa.

41 La mayoría de los actos de intolerancia hacia los grupos religiosos minoritarios, en México, se cometen en contra de los protestantes. Consecuentemente, vale la pena recordar en qué consisten estos actos y los motivos que, históricamente, se han utilizado para justificarlos. Las formas más "ligeras" de intolerancia son las ofensas, la falta de respeto y las burlas. Con respecto a esta tendencia, vale la pena citar un chiste utilizado sobre todo por las clases medias mexicanas, que menciona Carlos Monsiváis (2010: 77):

El padre se entera de la profesión non sancta de la hija, se enfurece y la amenaza con la expulsión: “¡Hija maldita! ¡Vergüenza de mi hogar! Dime otra vez lo que eres para que maldiga mi destino". Se hace un silencio y la hija murmura: "Papá, soy prostituta". Suspiro de alivio y el rostro paterno se dulcifica: “¿Prostituta? ¡Ah, bueno!, yo creía que habías dicho protestante".

El problema es que, muy a menudo, el chiste "Se vuelve tradición hogareña y hay el rumor de que el primero que lo dijo fue san Pedro" (Monsiváis, 2010: 77). Desafortunadamente, la hostilidad hacia los protestantes, en México, no se limita sólo a la burla o al chiste. Muy frecuentes son la expulsión de la comunidad, la privación ilegal de la libertad, las lesiones y el asesinato ${ }^{6}$. Uno de los pretextos principales que, históricamente, se ha utilizado para justificar estas formas, más o menos graves, de discriminación y violencia, consiste en la acusación, para los grupos protestantes, de representar una amenaza para la independencia de América Latina (Bastian, 2011a: 22). Estas acusaciones se remontan a las campañas católicas que, en los años veinte del 1900, culpaban a los grupos protestantes de formar parte de una

Conspiración del liberalismo y de la francmasonería, que favorecía la eventual anexión por parte de Estados Unidos de ciertos territorios latinoamericanos. Más aún, ante las intervenciones militares estadounidenses, más frecuentes desde principios del siglo, los intelectuales católicos salieron en defensa de los valores hispánicos de América Latina. (Bastian, 2011b: 182)

Más específicamente, en México, estas inculpaciones se concretaron sobre todo durante el periodo 1940-1960, cuando el Estado y la Iglesia Católica se juntaron para "detener brutalmente al protestantismo" (Monsiváis, 2010: 72), igualmente acusado de formar parte de la "estrategia de los gringos para debilitar a los pueblos de raíz hispánica" y atentar, por lo tanto, a la pureza de la identidad nacional. Por lo tanto, en México (y, en 
general, en América Latina), los orígenes de la violencia racista hacia los protestantes parecen ser, principalmente, de tipo identitario (Wieviorka, 2009: 99-102). Esta maniobra de aniquilamiento de los protestantes mexicanos, según Monsiváis (2010: 77), se puede resumir en una palabra: sectas.

Las sectas - de acuerdo con el Episcopado y sus numerosos aliados- son la oscuridad en las tinieblas (así de reiterativo), de ritos casi demoniacos que apenas disfrazan la puerilidad, de los servicios religiosos que a los Verdaderos Creyentes les resultan indignantes y risibles, de la compra de la fe de los indecisos y los ignorantes. La noción de las sectas autoriza a los Creyentes Auténticos para hacer con los sectarios lo que su fe autoriza. Y el disgusto ante lo distinto legitima los ejercicios del odio. (Monsiváis, 2010: 77)

Como consecuencia de estas campañas, hubo muchos asesinatos y actos de vandalismo en nombre de la fe católica y de la defensa de la identidad nacional que, raramente, fueron reportados por los medios de comunicación. El problema del tratamiento dedicado a las minorías religiosas por parte de los medios masivos de comunicación representa un aspecto importante, que aquí merece ser profundizado. Como lo ha hecho notar Monsiváis (2010: 75):

La inculpación de extranjería afecta a los grupos protestantes en lo externo y en lo interno. Los protestantes o evangélicos están al tanto del tamaño de la calumnia, pero no tienen manera de contestar, los medios están cerrados y sus publicaciones apenas circulan en su radio de acción. (p. 75)

Eso pasa porque, en México, como destacado por Masferrer Kan (2009), "la inmensa mayoría de los medios está en manos de propietarios católicos” (p. 99). No hay que olvidar que, como planteado por Van Dijk (1997: 78), las características sociales, económicas y culturales de los gatekeepers favorecen la producción de mensajes que tienden a reproducir y legitimar la ideología de las élites políticas, socioeconómicas y culturales (Van Dijk, 1997: 78) dominantes en una sociedad. El resultado es la no representación de las minorías, es decir su "anulación simbólica de la agenda", que Ishibashi (2004) explica a través de las siguientes palabras:

No sólo es el estereotipo en los medios el que reproduce el prejuicio, sino que también la ausencia o poca presencia de grupos minoritarios es considerada como el centro mismo del problema, debido al poderoso efecto simbólico de amarrar a aquellos de minorías en el estrato más bajo de la jerarquía económica, política, social y de cultura dentro del estado nacional. (p. 4)

En otras palabras, en los medios masivos de comunicación, el racismo hacia los grupos protestantes mexicanos (y, en general, hacia las religiones no católicas): "reside en la no representación, en la negación, que es una denegación de existencia social y de humanidad" (Wieviorka, 2009: 162). Las raras veces que los medios masivos de comunicación han abordado el tema, lo han hecho para criticar a los protestantes y para confirmar su acción nociva hacia la conservación de la identidad y la cultura mexicanas, como lo demuestra el siguiente relato de Monsiváis:

En 1990, en un programa del Canal 13, la locutora se mostró indignada: en la frontera norte hay una ciudad con más templos de "sectas que cantinas. “Por qué es esto tan nocivo?", le pregunté, y respondió con presteza; “Por lo menos en las cantinas no se pierde la identidad nacional. (Monsiváis, 2010: 81)

La intolerancia hacia los grupos protestantes mexicanos ha seguido hasta la fecha, avalada por el poder político y el mediático, alimentada por el poder religioso de la Iglesia Católica, y muy a menudo ejecutada por la gente común, en los pueblos y en las ciudades. 
48 Antes de concluir este apartado, vale la pena recordar que, en los últimos años, en México, la intolerancia religiosa se ha concentrado también en algunos nuevos cultos y movimientos religiosos populares, muy a menudo surgidos dentro el catolicismo, pero no reconocidos por las jerarquías eclesiásticas. La estrategia utilizada para justificar los ataques hacia estos grupos se basa, como en el caso de los protestantes, en la construcción, por parte del grupo mayoritario (el catolicismo), de una heteroidentidad ${ }^{7}$ que resalta todos los aspectos negativos (además no demostrados) del grupo minoritario (Cuche, 1999: 112-113). Un ejemplo emblemático es, seguramente, el del culto a la Santa Muerte, que viene representado como doblemente peligroso para la sociedad mexicana: porque ha sido asociado, sin ninguna prueba al respecto (Perdigón, 2008), con el narcotráfico (Hernández Sánchez, 2009) y porque amenaza su pretendida unidad católica.

Como consecuencia de estas representaciones negativas, que los medios de comunicación se encargan de reproducir y ampliar, recientemente, se han registrado varios actos de violencia en contra de los devotos de la "Santa", tales como la destrucción de altares, la negación de servicios básicos (como agua, gas, luz y servicios de salud) por parte de las autoridades y hasta las persecuciones judiciales por parte de policías y magistrados, utilizando, como pretexto, los presuntos vínculos de esta devoción con el narcotráfico (Hernández Sánchez, 2009: 116).

50 A la luz de todo lo que hemos visto, es pertinente concluir este apartado recordando que la situación para los integrantes de las religiones no católicas en México, parece bastante compleja y, si no viene solucionada pronto, podría desembocar en un escenario cada vez más explosivo y difícil de controlar.

\section{A modo de conclusión: "Hasta ahora, todo va bien"}

51 Sintetizando las temáticas principales abordadas en el texto, vale la pena empezar recordando que, como consecuencia de la afirmación de la conciencia moderna, el campo religioso funciona como un mercado económico en el cual las iglesias y grupos religiosos se comportan como empresas, que compiten para conquistar cada vez más "clientes", diferenciando su oferta de bienes simbólicos.

Esta situación ha representado, históricamente, el terreno fértil gracias al cual ha podido desarrollarse el "pluralismo religioso", concebido como sinónimo de diversidad y definido como "la creciente fragmentación de los sistemas de creencia" (Davie, 2011: 206).

53 En México, esta fragmentación de los sistemas de creencia se ha dado, como en toda América Latina, a partir de los años cincuenta del siglo XX, como consecuencia de procesos sociales exógenos y endógenos. El grupo religioso minoritario que en estos sesenta años ha crecido más en México, es el de los protestantes y evangélicos que, en 2010, ha alcanzado el 7,46\% de la población nacional.

En este contexto de creciente diversificación del campo religioso, pero todavía caracterizado por el monopolio del catolicismo $(82,70 \%$ de la población nacional, en el 2010), existe un "problema intolerancia" hacia las minorías religiosas. El marco teórico que hemos utilizado para poder interpretar este fenómeno, se basa principalmente en el concepto de racismo. Después de haber proporcionado la definición de racismo biológico (Wieviorka, 2009), hemos decidido utilizar el concepto, más específico y pertinente para los objetivos de nuestro estudio, de racismo cultural (Barker, 1981), que se enfoca en la diferencias culturales en lugar de las físicas. 
55 En cuanto a las prácticas de racismo hacia las minoría religiosas, como resultado de la presente investigación, emerge un modelo con base en el cual es posible identificar dos formas principales de racismo religioso presentes en el país: 1) el racismo institucionalizado (Wieviorka, 2009: 107), perpetrado por parte de las autoridades federales, estatales y locales y por parte de las instituciones eclesiásticas; 2) el racismo simbólico (Kinder y Sears, 1981; Pettigrew, 1989), más sutil e indirecto, cuyos sujetos son, en general, todas aquellas personas comunes que, entrevistadas, consideran positivo para la sociedad el aporte de la diversidad religiosa. Además, ambas, son formas de racismo que se basan en formas de violencia, tanto simbólica como física, de tipo identitario, en cuanto expresan la "reacción ante un sentimiento de amenaza que pesa sobre la identidad colectiva" (Wieviorka, 2009: 99). El grupo principal que en este contexto ha sufrido, históricamente, de la intolerancia religiosa es el de los protestantes.

Las formas de racismo hacia los protestantes se han encuadrado dentro de verdaderas estrategias de aniquilamiento del adversario, llevadas a cabo por la Iglesia católica y el Estado mexicano a partir de los años cuarenta del 1900 y hasta la fecha, utilizando el pretexto de que eran grupos al sueldo de los "gringos", que querían favorecer la anexión de América Latina a Estados Unidos y que, por lo tanto, amenazaban la pureza y conservación de la identidad nacional. Con base en lo anterior, no podemos descartar la posibilidad de que, en un futuro próximo o lejano, en nombre de la defensa de la identidad nacional, también en México pueda surgir una de aquellas identidades predatorias de las cuales habla Appadurai, cuyo objetivo principal es "eliminar la distancia que existe entre la mayoría y la pureza del todo nacional" (Appadurai, 2007: 71). Como destacado por Wieviorka (2009: 100), los orígenes identitarios de la violencia racista, no hay que olvidarlo, pueden conducir "a una violencia ilimitada". Los instrumentos (el privilegio del diálogo y de la conciliación entre las partes utilizado por la Dirección General de Asuntos Religiosos) que hasta la fecha se han utilizado para solucionar el problema de la intolerancia religiosa en México, aparecen demasiado blandos y, por lo tanto, totalmente inadecuados.

Urge pensar en mecanismos más eficientes, que se enfoquen sobre todo en la prevención de la intolerancia en todos los niveles de la sociedad (escolares, medios de comunicación, puestos de trabajo, política, etc.), a través de una educación hacia la tolerancia religiosa que, como destacado por Sartori (2000), representa la base realística, no utópica, para la afirmación de un pluralismo que reconoce y respeta la diferencia. La alternativa es quedarse a mirar, con los brazos cruzados, los micro conflictos, disputas y actos de violencia cotidianos hacia las minorías, pensando que no desembocarán nunca en algo más grave, como en el cuento judío parafraseado en la parte final de la película el odio (Kassovitz, 1995), en el cual se narra la historia de una sociedad que se cae y que se repite sin cesar, para tranquilizarse, "Hasta ahora, todo va bien. Hasta ahora, todo va bien. Hasta ahora, todo va bien". Porque lo importante no es la caída, sino el aterrizaje. 


\section{BIBLIOGRAFÍA}

ADOGAME, A. (2010), "Pentecostal and Charismatic Movements in a Global Perspective", En Turner B. S. (coord). The New Blackwell Companion To The Sociology Of Religion. Oxford: Blackwell Publishing.

APPADURAI, A. (2007), El rechazo de las minorías. Ensayo sobre la geografía de la furia. Barcelona: Tusquets Editores.

AUBRÉE, M. (2013), "Latin-American and Asiatic Neo-Protestantisms: A Comparative Study". Social Compass, 60 (4): 517-526.

BARKER, M. (1981), The New Racism. Londres: Junction Books.

BASTIAN, J. P. (2011a), La mutación religiosa de América Latina. Para una sociología del cambio social en la modernidad periférica. México: FCE.

BASTIAN, J. P. (2011b), Protestantismo y Modernidad Latinoamericana, historia de unas minorías religiosas en America Latina. México: Fondo de Cultura Economico.

BERGER, P. (1987), L'imperativo eretico. Possibilità contemporanee di affermazione religiosa. Torino: Elle Di Ci.

BERGER, P. L., y LUCKMANN, T. (1997), Modernidad, pluralismo y crisis de sentido. La orientación del hombre moderno. Barcelona: Paidós.

BLANCARTE, R. (2008), Libertad religiosa, estado Laico y no discriminación. México:CONAPRED.

BLANCARTE, R. (2010), “Las identidades religiosas de los mexicanos”, en R. Blancarte (coord.). Los grandes problemas de México. Culturas e Identidades. México: El Colegio de México.

BLUMER, H. (1958), "Race Prejudice As Sense Of Group Position”. The Pacific Sociological Review. Vol. 1, n. 1: 3-7.

CANNARIATO, A. (2013), “Origini e sviluppi dei pentecostali”, in Chiapas. En E. Segre Malagoli y S. Scotti. Immaginari del cambiamento in America Latina. Religioni, culture, dinamiche económico- sociali. Mauro Pagliai Editore: Firenze.

CARMICHAEL, Stokely y HAMILTON, Charles V. (1967), Black Power: the Politics of Liberation in America. Nueva York: Vintage Books.

CHESNUT, A. (2003), Competitive Spirits. Latin America's New Religious Economy. New York: Oxford University Press.

CONAPRED. (2010). Encuesta Nacional sobre discriminación en México/Enadis del 2010. Resultados sobre diversidad religiosa. México: CONAPRED.

CORBETTA, P. (2007), Metodología y técnicas de investigación social. Madrid: McGraw-Hill. CUCHE, D. (1999), La noción de cultura en las ciencias sociales. Buenos Aires: Nueva Visión. DAVIE, G. (2011), Sociología de la religión. Madrid: AKAL.

DE LA TORRE, R. y ZÚÑIGA, C. G. (2007), Atlas de la diversidad religiosa en México. México: Type. DOBBELAERE, K. (2004), Secularization: An Analysis at Three Levels. Brussels: P.I.E. 
FILORAMO, G. (2005), "Le religioni di fronte alla sfi da della globalizzazione”, en G. Filoramo, E. Gentile, \& G. Vattimo, Cos'è la religione oggi? Pisa: ETS.

FORTUNY, P. (1993), “Cultura política entre los Protestantes en México”, in J. Alonso, Cultura, Politica y Educación Cívica. México: Editorial Porrua.

FRESTON, P. (2007), "Latin America: The "Other Christendom", Pluralism and Globalization", en P. Beyer y L. Beaman (Ed.). Religion, Globalization and Culture. USA: BRILL.

GARMA NAVARRO, C. (1987), Protestantismo en Comunidad Totonaca de Puebla. México.

GARMA NAVARRO, C. (2004), Buscando el Espíritu. Pentecostalismo en Iztapalapa y la Ciudad de México. México: UAM.

GARMA NAVARRO, C., y LEATHAM, M. C. (2004), "Pentecostal Adaptations in Rural and Urban Mexico: An Anthropological Assessment”. Mexican Studies/Estudios Mexicanos, vol. 20, n. 1: 145-166.

GIDDENS, A. (2007), Sociología, Madrid: Alianza Editorial.

GILL, A. (1998), Rendering Unto Caesar. The Roman Catholic Church and the State in Latin America. Chicago: University of Chigago Press.

HERNÁNDEZ SAMPIERI, R.; COLLADO, C. F.; BAPTISTA, L. M. (2010), Metodología de la investigación. Perú: McGraw Hill.

HERNÁNDEZ SÁNCHEZ, M. A. (2009), Tres análisis de caso de discriminación por motivos religiosos: el uso del velo por las mujeres islamistas, la situación de las personas que practican una religión distinta a la mayoritaria en pueblos y comunidades indígenas y el culto a la muerte. México: CONAPRED.

HERVIEU-LÉGER, D. (2003), Il pellegrino e il convertito. La religione in movimiento. Bologna: il Mulino.

INEGI (2010). Censo de Población y Vivienda 1950-2010. http://www.inegi.org.mx/est/ contenidos/proyectos/ccpv/.

ISHIBASHI, J. (2004), Hacia una apertura del debate sobre el racismo en Venezuela: exclusión e inclusión estereotipada de la persona "negra" en los medios de comunicación. Caracas: Colección Monografías.

KARSTEDT, S. (2009), “Tolerance”, en G. Ritzer, The Blackwell Encyclopedia of Sociology. USA: Blackwell Publishing.

KASSOVITZ, M. (Dirección) (1995), La Haine [Película].

KINDER, D. R. y SEARS, D. O. (1981), "Prejudice and politics: symbolic racism versus racial threats to the good life". Journal of Personality and Social Psychology. 40, n. 3, 414-431.

LUCKMANN, T. (1969), La religione invisibile. Bologna: il Mulino.

MASFERRER KAN, E. (2009), Religión, poder y cultura. Ensayos sobre la política y la diversidad de creencias. México: Libros de la Araucaria.

MARTIN, R. D. (1990), Tongues of Fire. The explosion of Protestantism in Latin America. Oxford: Blackwell.

MARTIN, D. (2002), Pentecostalism: The World Their Parish, Oxford: Blackwell.

MERTENS, D. M. (2010), Research And Evaluation In Education And Psychology: Integrating Diversity With Quantitative, Qualitative, And Mixed Methods. USA: Sage. 
MONSIVÁIS, C. (2010), “De la variedades de la experiencia protestante”, en Blancarte, R. (coord.). Los grandes problemas de México. Culturas e identidades. México: El Colegio de México.

OROZCO, G. y GONZÁLEZ, R. (2011), Una coartada metodológica. Abordajes cualitativos en la investigación en comunicación, medios y audiencias. México: Tintable.

PERDIGÓN, K. (2008), La Santa Muerte protectora de los hombres. México: INAH.

PETTIGREW, T.S. (1989), "The nature of modern racism in the United States". Revue Internationale de Psychologie Sociale, Vol.2, n. 3, 291-304.

SARTORI, G. (2000), Pluralismo, multiculturalismo e estranei. Saggio sulla società multietnica, Milano: Rizzoli.

SCOTT, L. (1997), Bibliografía de los Evangelicos en México. México: Visión Evangelizadora Latinoamericana.

STOLL, D. (1990), Is Latin America Turning Protestant? The Politics of Evangelical Growth. Berkeley: University of California Press.

VAN DIJK, T. A. (1997), Racismo y análisis crítico de los medios. España: Paidós Comunicación.

WIEVIORKA, M. (2009), El racismo: una introducción. Barcelona: Gedisa.

WEBER, M. (2009), El político y el científi co, Madrid: Alianza Editorial.

\section{NOTAS}

1. En los trabajos de tipo descriptivo y exploratorio, generalmente, no se plantean hipótesis (Hernández Sampieri, Collado, Baptista, 2010: 79-81; Orozco y González, 2011: 45), sino objetivos o propósitos que, en el caso de los estudios descriptivos consisten en describir las características o propiedades de un fenómeno (en nuestro estudio: objetivos 1 y 2) y, en el caso de los exploratorios, en desarrollar, como resultado final, modelos, hipótesis y tendencias (en nuestra investigación: el objetivo 3).

2. La pluralización del campo religioso mexicano y la intolerancia hacia las minorías religiosas que, hasta la fecha, han sido muy poco estudiadas en el contexto mexicano.

3. Este modelo es muy parecido al "racismo institucional" (Carmichael y Hamilton, 1967), que destacan el papel, más o menos activo y más o menos explícito, de todas las instituciones en las prácticas discriminatorias.

4. El "Programa Progresa" es un programa federal mexicano para el desarrollo humano de la población en pobreza extrema, que brinda apoyos en educación, salud, nutrición e ingresos.

5. La violencia simbólica, según Wieviorka (2009: 87), es aquel tipo de violencia que afecta a la integridad moral (desprecio, prejuicio, odio) de una persona, sin consecuencias para su integridad física.

6. El caso más conocido es el de San Juan Chamula (Cannariato, 2013), en Chiapas, donde los evangélicos fueron víctimas de violaciones, expulsiones y asesinatos, a partir del año 1996 y hasta la fecha. Sin embargo, existen muchos otros casos de intolerancia religiosa grave hacia los grupos protestantes, registrados en Chiapas, Oaxaca, el Estado de México, Hidalgo, entre otros.

7. Para un grupo minoritario, la "heteroidentidad" es la imagen de sí construida por un grupo mayoritario. 


\section{RESÚMENES}

Los tres principales objetivos de este trabajo son reconstruir los procesos de diferenciación del campo religioso mexicano, describir las prácticas de intolerancia hacia las minorías religiosas y determinar las formas de racismo que ocurren en estas prácticas. Estos objetivos nos permiten constatar que, en México, existe un problema grave de "intolerancia hacia las minorías religiosas" y que la manera de manejar este problema ha sido, hasta la fecha, ineficaz. Para afirmar lo anterior, nos apoyamos en un marco teórico que, desde una perspectiva interdisciplinaria, se enfoca en los conceptos de "pluralismo religioso" y "racismo". Las conclusiones señalan la necesidad de desarrollar mecanismos más eficientes en defensa de la diversidad religiosa de los que se han utilizado hasta la fecha, para aspirar a la construcción de sociedades basadas realmente en la tolerancia y, consecuentemente, en la convivencia pacífica de las diferencias.

Os três principais objetivos deste trabalho são reconstruir os processos de diferenciação do campo religiosos mexicano, descrever as práticas de intolerância em relação às minorias religiosas e determinar as formas de racismos que ocorrem nestas práticas. Estes objetivos permitem-nos constatar que, no México, existe um problema grave de "intolerância para com as minorias religiosas" e que a maneira de lidar com esse problema tem sido, até à data, ineficaz. Para confirmar este facto partimos de um quadro teórico que, numa perspetiva interdisciplinar, assenta nos conceitos de "pluralismo religioso" e "racismo". As conclusões mostram a necessidade de desenvolver mecanismos mais eficazes de defesa da diversidade religiosa do que aqueles que têm sido utilizados até à data, para aspirar à construção de uma sociedade realmente baseada na tolerância e consequentemente na convivência pacífica das diferenças.

The three main objectives of this work are to reconstruct the processes of differentiation of Mexican religious field, describe the practices of intolerance towards religious minorities and determine the forms of racism that occur in these practices. These objectives allow us to observe that, in Mexico, there is a serious problem of "intolerance towards religious minorities" and that the way to handle this problem has been, to date, ineffective. To affirm this, we rely on a theoretical framework that, from an interdisciplinary perspective, focuses on the concepts of "religious pluralism" and "racism". The findings indicate the need to develop more efficient mechanisms of defense of religious diversity that have been used to date, to aspire to build societies actually based on tolerance and, consequently, in the peaceful coexistence of differences.

\section{ÍNDICE}

Keywords: Mexico, religion, pluralism, minorities, intolerance, racism

Palavras-chave: intolerância religiosa, minorias, racismo, diferenciação

Palabras claves: México, religión, pluralismo, minorías, intolerancia, racismo 


\section{AUTOR}

\section{FRANCESCO GERVASI}

Universidad Autónoma de Coahuila. Enderezo de correspondencia: Sin Nombre de Colonia, Monclova, COAH, México

francescogervasi@uadec.edu.mx 